\title{
Matricaria urea extract exhibits antinociceptive activity in male rat Mojtaba Khaksarian*
}

\author{
Address: Medical Biology Research Center, Iran \\ * Corresponding author
}

\author{
from International Society on Brain and Behaviour: 2nd International Congress on Brain and Behaviour \\ Thessaloniki, Greece. 17-20 November 2005 \\ Published: 28 February 2006 \\ Annals of General Psychiatry 2006, 5(SuppI I):SI66 doi:I0.1 I86/I744-859X-5-SI-SI66
}

\section{Background}

The aim of the present study was to explore the probable antinociceptive effects of Hydroethanolic extract of Matricaria urea $(\mathrm{Mu})$ in experimental models of acute pain (Tail flick) and chronic pain (Formalin test).

\section{Materials and methods}

Effects of Mu extract were assessed with the antinociceptive effects of sodium salicylate (SS) $200 \mathrm{mg} / \mathrm{kg}$ as a positive control. The results are expressed as mean \pm SEM and the difference was analyzed by means of ANOVA followed by Tukey test.

\section{Results}

Antinociceptive of $200 \mathrm{mg} / \mathrm{kg}$ of SS (i.p) had no effect on Tail flick latency, while all doses $(250,500 \mathrm{mg} / \mathrm{kg})$ of extract, increased this latency (at least $\mathrm{p}<0.05$ ). SS produced antinociceptive only in the Second phases of formalin test $(p<0.05)$, while in the first phase it's not effective. All doses of $\mathrm{Mu}$ extract showed a significant effect on both phases of formalin test (at least p < 0.01). The lethal dose (LD50) of extract was about $4000 \mathrm{mg} / \mathrm{kg}$.

\section{Discussion}

In generally Mu extract has effect on the Tail-flick latency and both phases of formalin test; the site of action is probably central and the mechanism of antinociceptive of extract remains to be elucidated

\section{References}

I. Elisabetsky E, Amodor TA, Albuquerque RR, Nunes DS, Carvalho ACT: Analgesic activity Psychotria colorata (Wild. ex R. and S.) Muell. Arg. alkaloids. J Ethnopharmacol 1995, 48:77-83.

2. D'Amour FE, Smith DL: A method for determining loss of pain sensation. J Pharmacol Exp Ther 194I, 72:74-79.

3. Dubusisson D, Deniss SG: The formalin test: a quantitative study, of the analgesic effects of morphine, meperidine, and brain stem stimulation in rats and cats. Pain 1977, 4:161-174.

4. Tjolsen A, Berge O, Hunskaar S, Rosland JH, Hole K: The formalin test: an evaluation method. Pain 1992, 5 I:5-17. 